NBER WORKING PAPER SERIES

\title{
DYNAMIC INEFFICIENCIES IN INSURANCE MARKETS: EVIDENCE FROM LONG-TERM CARE INSURANCE
}

\author{
Amy Finkelstein \\ Kathleen McGarry \\ Amir Sufi \\ Working Paper 11039 \\ http://www.nber.org/papers/w11039 \\ NATIONAL BUREAU OF ECONOMIC RESEARCH \\ 1050 Massachusetts Avenue \\ Cambridge, MA 02138 \\ January 2005
}

We thank Bengt Holmstrom for helpful comments and the National Institute of Aging (Finkelstein and McGarry) and the Boston College Center for Retirement Research (Sufi) for financial support. The views expressed herein are those of the author(s) and do not necessarily reflect the views of the National Bureau of Economic Research.

(C) 2005 by Amy Finkelstein, Kathleen McGarry, and Amir Sufi. All rights reserved. Short sections of text, not to exceed two paragraphs, may be quoted without explicit permission provided that full credit, including (C) notice, is given to the source. 
Dynamic Inefficiencies in Insurance Markets: Evidence from long-term care insurance Amy Finkelstein, Kathleen McGarry, and Amir Sufi

NBER Working Paper No. 11039

January 2005

JEL No. D4, D8, I11, G22, J14

\begin{abstract}
We examine whether unregulated, private insurance markets efficiently provide insurance against reclassification risk (the risk of becoming a bad risk and facing higher premiums). To do so, we examine the ex-post risk type of individuals who drop their long-term care insurance contracts relative to those who are continually insured. Consistent with dynamic inefficiencies, we find that individuals who drop coverage are of lower risk ex-post than individuals who were otherwiseequivalent at the time of purchase but who do not drop out of their contracts. These findings suggest that dynamic market failures in private insurance markets can preclude the efficient provision of insurance against reclassification risk.
\end{abstract}

\author{
Amy Finkelstein \\ National Bureau of Economic Research \\ 1050 Massachusetts Avenue \\ Cambridge, MA 02138 \\ and Harvard Society of Fellows \\ afinkels@nber.org \\ Kathleen McGarry \\ National Bureau of Economic Research \\ 1050 Massachusetts Avenue \\ Cambridge, MA 02138 \\ and UCLA \\ mcgarry@ucla.edu \\ Amir Sufi \\ Department of Economics \\ MIT \\ 50 Memorial Drive \\ Cambridge, MA 02142 \\ sufi@mit.edu
}




\section{Introduction}

Most analyses of insurance market failures have been in a static, one-period setting, with considerably less attention devoted to considering the problems that may arise in a multi-period (dynamic) context. In a dynamic framework, risk averse individuals benefit not only from periodby-period "event" insurance, but also from insurance against becoming a bad risk and being reclassified into a higher risk group with a concomitant increase in premiums. We refer to this latter possibility as "reclassification risk." From an ex-ante perspective, insurance against this reclassification risk can provide substantial welfare benefits (Hirshliefer 1971).

Contracts that provide full insurance against reclassification risk are easily constructed in theory (Cochrane 1995, Pauly et al. 1995) but it is unclear whether they exist in practice. In this paper we examine empirically the extent to which the private market efficiently provides insurance against the probability of reclassification by analyzing the private market for long-term care insurance in the United States. This market has substantial reclassification risk: differences in premiums between risk categories are large, as is the likelihood that an individual will experience a change in risk classification over time. However, we present evidence suggesting that despite the potential efficiency gains, the private market does not provide full insurance against reclassification risk. Specifically, we find evidence of risk-based dynamic selection; individuals who drop their long-term care insurance contracts are, ex-post, of substantially lower risk than otherwise identical-looking individuals who retain coverage. This dynamic selection implies that over time the long-term care insurance market becomes more adversely selected. Furthermore, because premiums must cover the expected cost to the insurer, those who become "bad risks" and who thus stay in the market, pay premiums reflecting the nature of the retained risk pool, thus precluding full insurance against reclassification risk.

\footnotetext{
${ }^{1}$ Cochrane (1995) refers to it as "premium risk."
} 
The long-term care insurance market is a particularly attractive setting to study these issues as it allows us to abstract from much of the regulatory environment applicable to other insurance markets. Whereas most insurance markets function in a heavily regulated environment, over the period of our study, premiums in the long-term care insurance market are essentially unregulated (Brown and Finkelstein, 2004). Previous work has argued that regulations may interfere with a market's functioning and be an important factor in the failure of markets to provide reclassification risk insurance (Cochrane, 1995).

More generally, the market for long-term care insurance is of substantial interest in its own right. With annual expenditures estimated to be $\$ 135$ billion in 2004, long-term care expenditures currently represent one of the largest uninsured medical and financial risks faced by the elderly in the United States. One third of long-term care expenditures are paid for out of pocket. This is double the proportion of overall health care expenditures paid for out of pocket (Congressional Budget Office 2004, National Center for Health Statistics 2002). As the baby boom generation ages and medical costs rise, the nature of the long-term care insurance market will have profound implications for the well-being of both the elderly and their children.

Despite the apparent value of insurance, only 10 percent of the elderly have any private longterm care coverage (Brown and Finkelstein 2004). Furthermore, there is as of yet, no agreed upon factor or set of factors responsible for its limited reach. Many theoretical explanations have been proposed (see Norton 2000 for a review), but to our knowledge, the potential role of dynamic selection has not been discussed. However, our results point clearly to the existence of dynamic market failures and thus raise the possibility that these failures may play a significant role in limiting the market's size. Our attention to the dynamic aspects of coverage also highlights the existence of another important form of risk in this market (other than the "event risk" of longterm care use) that may be underinsured: the risk of reclassification.

\section{Reclassification risk in the market for long-term care insurance}


Long-term care insurance prices vary with the individual's health status at the time of purchase. Individuals who defer the purchase of a policy and who experience a decline in health, thus face the reclassification risk of being put in a higher price bracket (i.e. worse health category). The difference in premiums across health classifications is large. Our analysis of the premium structure of one large long-term care insurer shows an increase in policy premiums of 175 percent when moving from a standard risk classification to a substandard (unhealthy) level.

More importantly, individuals in observably poor health are usually denied insurance coverage altogether (Murtaugh et al., 1995; Weiss, 2002). ${ }^{2}$ This points to potentially large reclassification risk, as the result of entering into an ineligible category is to be shut out of the market completely (i.e. face an infinite price). Moreover, the risk of being denied insurance is non-trivial. Using 2002 information, we identified the denial practices of major writers of longterm care insurance and found that coverage is simple categorically denied to any individuals who have limitations with respect to activities of daily living (bathing, eating, dressing, toileting, walking), require the assistance of mechanical devices (wheelchair, walker, crutches, quad cane, oxygen) or suffer from cognitive impairment. Based on this practice, we estimate in the 2000 Health and Retirement Survey that the risk of ineligibility increases sharply with age, from only 8 percent of 50-54 year olds to 33 percent of individuals aged 75 and older.

\section{Market failure for reclassification risk insurance: The Hendel and Lizzeri (2003) model}

Although discussions of the efficient operation of insurance markets tend to focus on the role of asymmetric information and the resulting problems of adverse selection and moral hazard, inefficiencies can also arise when information is symmetric. If information is symmetric and the market is competitive, the premium the individual faces will be actuarially fair conditional on his

\footnotetext{
${ }^{2}$ This practice is surprising given the absence of pricing regulation preventing the offering of high prices. It may reflect issues of reputation or brand name, private market failures such as asymmetric information which may be more of a problem for people in worse health, or the existence of very little residual variance in expenditures to insure (and hence little insurance value) for individuals in observably poor health.
} 
known risk. In a multi-period setting, additional information about the individual's risk will be (perhaps symmetrically) revealed over time, and his premium will be adjusted accordingly. An individual who is revealed to be of higher than expected risk will face a rise in price. Given this potential, risk averse agents will wish to purchase insurance against the possibility of being reclassified as a higher risk. Optimal insurance contracts therefore provide protection against both the "event risk" and this "reclassification risk."

The important theoretical and empirical question is whether in fact an unregulated insurance market will efficiently provide the full reclassification risk insurance demanded by risk averse consumers. Cochrane (1995) has argued on a theoretical basis that such insurance can be provided efficiently by the private market, and attributes the apparent lack of such insurance in many markets to regulatory constraints. Hendel and Lizzeri (2003) however show that the market is unlikely to function efficiently if individuals and insurance companies learn symmetrically over time about the individual's risk type, individuals cannot commit to stay in a contract upon the revelation of favorable information, and there are liquidity constraints.

These assumptions seem reasonable ones for many current insurance markets. In practice we see that while firms can commit to providing continued coverage at a specified premium, individuals cannot be required to pay premiums on a policy they no longer wish to hold. Commitment in these markets is thus one-sided, resulting in a loss of full reclassification risk insurance; for individuals who learn that they are of better than expected risk would have an incentive to select out of the original contract and into one with a more favorable premium structure. A more favorable premium structure will be offered by a firm who has (symmetrically) learned that the individual is of better than expected risk.

An obvious solution to this commitment problem is for policies to be pre-paid. If individuals pay the expected presented discounted value of all future premiums up front, they will have no incentive to select out of the contract as new information is revealed. Thus complete pre-payment, or full front-loading of the contract will solve the one-sided commitment problem and enable the 
market to provide full insurance against reclassification risk. However, liquidity constraints are likely to prohibit the complete up-front payment of all premiums leading to market failure in the provision of reclassification insurance.

Although Hendel and Lizzeri (2003) develop and test their model in the context of the life insurance market, it is obviously applicable to the long-term care insurance market as well. Indeed, the assumption that binding liquidity constraints prevent full front loading seems particularly well suited to a market such as the long-term care insurance market in which - unlike the life insurance market -the risk insured is not proportional to income and therefore liquidity constraints may be even more binding.

\section{Market characteristics and preliminary evidence of dynamic inefficiencies in the long- term care insurance market}

A straightforward implication of the Hendel and Lizzeri (2003) model is that in equilibrium insurance contracts should exhibit at least some degree of front-loading, in order to reduce individuals' incentives to seek a new contract if they learn that they are of better than expected risk. The extent of front loading will vary with the extent of liquidity constraints.

Consistent with this prediction, long-term care insurance contracts are in fact front loaded, to varying degrees. All long-term care insurance premiums are paid on a periodic (usually annual) basis at a pre-specified fixed, nominal rate determined at the time of purchase. In practice, policies are sold as guaranteed renewable and are not experience rated for the individual; thus the premium agreed to at the time of purchase is unaffected by subsequent health realizations or changes in the likelihood of the use of long-term care services. While premiums are thus declining over time in real terms, the expected value of a year of coverage rises as health deteriorates. Thus long-term care insurance contracts are substantially front loaded; individuals pay premiums that are initially higher than the actuarial cost, but as their risks rise, the ratio of premium to risk falls.

The extent of front-loading varies across contracts. While all contracts specify a constant 
nominal premium payment, some contracts specify a constant nominal benefit profile while others specify benefits that are escalating over time in nominal terms. Contracts in which the nominal benefits increase annually are more front loaded than contracts with constant nominal benefits.

In practice, holders of long-term care insurance policies typically make payments for quite a while before the risk of needing care becomes high. Although private insurance coverage tends to be bought relatively late in life - the average age of purchasers in 2000 was 67 (HIAA 2000) - it is still purchased on average substantially before the expected age of nursing home entry. For example, the average nursing home entry age for a typical non-institutionalized 65 year old (conditional on entering at all) is 83 , approximately 15 years after the average age at purchase (Brown and Finkelstein 2004). Dropping or changing policies is thus costly to the insured as he will already have pre-paid some of his future premiums on the current contract. In addition, the vast majority of long term care policies sold do not have a surrender value and lapse activity almost always results in the forfeiture of any future benefits (Brown and Finkelstein 2004).

Despite the implicit costs, dropping or changing policies is not uncommon in this market. The long-term care insurance industry uses the term "lapsation" to describe a policy termination for a reason other than death. Numerous protections exist to guard against unintentional dropping of coverage, so it is likely that the vast majority of these lapses are voluntary and deliberate. ${ }^{3}$ About 7 percent of in-force policies each year are cancelled due to the failure to make the regularly scheduled premiums (Society of Actuaries, 2002). ${ }^{4}$ Data for the Society of Actuaries indicate that the probability of a lapse is a U-shaped function of policy-duration (Figure 1) with

\footnotetext{
${ }^{3}$ Insurers provide numerous warnings before dropping coverage and will re-issue a policy even after a final warning has been sent if the lapse was made in error. Policy holders can also choose to have a third party notified in the event a premium is missed and they may elect a forfeiture provision specifying a reduced payment for future care should the need arise after a policy has been dropped. (See Kaiser Family Foundation 2003 for a discussion).

${ }^{4}$ It is possible that these data may overstate lapse rates as terminations for unknown reasons (which may include death) are counted as a lapse. However, a survey on this issue indicates that less than $10 \%$ of recorded lapses may in fact be deaths (HIAA, 1993) so any overstatement is likely to be quantatively small.
} 
the highest rates immediately after the policy is purchased and up to 12-15 years afterwards.

There is about a one-third cumulative probability of a policy having lapsed 5 years after purchase, and a 50 percent chance 10 years after purchase. For any policy duration, lapse rates are higher among less front-loaded policies, i.e. policies whose benefits are constant in nominal terms over time have lower rates of lapsing than those for which nominal benefits are increasing over time (Figure 2). The rates at which policies are allowed to lapse are similar across gender and across policies with different premium schedules (i.e. monthly, quarterly, annually or semi-annually).

Many of those who drop coverage exit the private market completely, rather than switch to a new policy. For example, in one inter-company follow-up survey, only about half of individuals who let their policy lapse reported that they had replaced it with another policy (HIAA, 1993). Similarly, in the HRS data (described below) we find that at most only one-quarter of those who report having lapsed on a policy in the past currently have insurance. ${ }^{5}$

As a result of the substantial front-loading and the absence of surrender or forfeiture benefits, this lapsation behavior can be quite costly to the individual. For example, Brown and Finkelstein (2004) estimate that the implicit cost of typical lapse behavior would raise the estimated average load on the typical long-term care insurance policy purchased by a 65 year old from 18 cents on the dollar (calculated assuming the individual does not lapse) to 51 cents on the dollar (calculated assuming the individual faces the population average probability of lapsing at each duration post purchase).

\section{Evidence of dynamic selection out of long-term care insurance contracts}

We now consider whether this lapsation behavior is consistent with the type of market failure for insurance against reclassification risk illustrated in the Hendel and Lizzeri (2003) model. Our analysis provides a complement to their empirical analysis of the life insurance market. Not only

\footnotetext{
${ }^{5}$ Of course, even those who do not purchase new private insurance still have some effective insurance coverage provided by Medicaid, the public insurance program for the poor.
} 
do we examine a different market, but more importantly, we focus on the behavior-based implications of the model rather than on the predictions for the design and pricing of insurance contracts that are developed and tested by Hendel and Lizzeri (2003). Specifically, we test the prediction that, in equilibrium, those who drop their insurance contract should, ex post, on average be lower risk than those who retain coverage. ${ }^{6}$

Insurance company records, such as those to which we referred above, provide information on who among policy holders let a policy lapse. However, they reveal nothing about what transpires subsequent to lapsastion (e.g. later nursing home use), nor about the individual's characteristics or circumstances at the time of the policy is dropped. If we are to examine the relative risks of lapsers and non-lapsers, such data are crucial. We therefore base our analysis on data from a nationally representative sample of older Americans.

Our data are drawn from the Health and Retirement Study (HRS). The HRS is a panel survey of the elderly and near-elderly with interviews administered approximately biennially beginning in 1992. As of the most recent survey year, 2000, the HRS consists of four distinct cohorts of respondents, each of whom have slightly different interview patterns. We will use observations for each of these cohorts although we note that the length of the observation window differs across groups. ${ }^{7}$

The HRS data provide detailed information on health status, insurance coverage, and other financial measures at each wave. They thus allow us to identify who among those with long-term care insurance lets their policy lapse, and how actual nursing home use varies between lapsers

\footnotetext{
${ }^{6}$ A natural reason for Hendel and Lizzeri's (2003) focus on contract-theoretic rather than behavior-based predictions is that, in their model, individuals who experience the biggest improvement in risk type between periods are just indifferent between staying in their original contract or moving to another contract. Therefore, although it may occur, one need not observe lapsation in equilibrium for their to be inefficient provision of reclassification risk insurance. Of course, the addition of other market frictions - for example other uninsured events such as income shocks - can be added to the model to produce a strict preference for lapsing.

${ }^{7}$ Details on the HRS and our working sample are presented in the appendix. A more complete description of the survey is available at http://hrsonline.isr.umich.edu/.
} 
and non-lapsers. This comparison provides a direct test of the prediction that those who let a policy lapse will be of lower subsequent risk of nursing home use.

A unique advantage of these data is that the survey directly asks individuals whether they have lapsed on a policy and thus do not require us to infer such behavior from periodic reports of insurance coverage which may be prone to measurement error. The specific question is: ${ }^{8}$

"Have you ever been covered by any long-term care insurance that you cancelled or let lapse."

We then observe whether the individual enters a nursing home at some point in the subsequent waves of the survey and compare the ex-post risk of nursing home use (the major source of longterm care expenditures) for those who drop coverage with those who retain their policy.

Specifically, we estimate:

$$
\text { NH_USE }=\mathrm{X} \beta_{1}+\beta_{2} \text { LAPSE }+\varepsilon
$$

The key coefficient of interest is that on LAPSE, our indicator for whether the individual has let his policy lapse. The vector $\mathrm{X}$ is comprised of controls for risk classification. The dependent variable in this regression measures the subsequent nursing home use of the individual defined as a stay of one or more nights. The sample mean of this binary variable is 0.069 .

A central issue in the analysis is defining the sample of individuals who are at risk for letting a long-term care policy lapse. We take as the universe of these "potential lapsers" the set of those who at some point had long term care coverage. Our main specification therefore includes individuals in the sample if they report having a long term care insurance policy, or if they report ever having let a policy lapse. The exact construction of our sample - as well as descriptions of alternative sample definitions to which we verified the results to be robust - are described in detail in the appendix.

Table 1 contains descriptive statistics on our sample, which consists of 987 individuals who report lapsing and 2662 individuals who were at risk for lapsing (i.e. reported having insurance)

\footnotetext{
${ }^{8}$ The appendix discusses this measure in more detail.
} 
but did not report lapsing. Comparing the characteristics of those who let a policy lapse and those who have coverage that does not lapse, we find that the individuals in the two groups are similar in age (average age of 66 and 67 respectively) and gender (44 and 45 percent male respectively). However, individuals who lapse are less likely to be married (63 compared to 72 percent), and are poorer and less educated than individuals who do not lapse. For example, the median net worth among those who lapse is $\$ 126,000$, compared to $\$ 218,000$ among those who do not lapse, and the percent with less than a high school education is 28 percent compared to 17 percent.

The model predicts that those who lapse do so because they learn that they are of lower than expected risk based on their characteristics when they purchased the policy. We would therefore like to compare individuals who were treated symmetrically by the insurance company and thus condition on their risk classification at the time the policy was purchased. Because our data do not extend back in time to when the policy was purchased, we use our best approximation by conditioning on what the individual's risk classification would have been in the first wave of data used for each cohort.

Finkelstein and McGarry (2003) discuss the risk classification practices of insurance companies in detail and how these can best be replicated in the HRS data. Here, we report two sets of results. The first excludes all covariates from the regression and thus provides an unconditional analysis of the relationship between lapsing behavior and subsequent nursing home use. The second specification controls for the characteristics of the individual used by the longterm care industry to predict an individual's expected nursing home use: age, gender, number of limitations to instrumental activities of daily living (IADLs), number of limitations to activities of daily livings (ADLs), and the presence or absence of cognitive impairment; all of this information is available in the HRS. ${ }^{9}$ We include these controls flexibly, with indicator variables for each age, number of ADLs, and number of IADLs.

\footnotetext{
${ }^{9}$ In results not shown, we also experimented with controlling for other health-related characteristics of the individuals as well. The results were unaffected.
} 
The results from linear estimation of equation (1) are shown in Table 2; probit estimation produces similar results (not shown). The relationship between a policy lapse (LAPSE) and subsequent nursing home use is significantly negative in both specifications, supporting the hypothesis that those who dropped coverage are less likely to use a nursing home than those who maintain coverage. Furthermore, the estimate is economically significant in that the difference in the probability of nursing home use between lapsers and non-lapsers is large. Average nursing home use in our sample is only about 7 percent, so these coefficients imply that nursing home entry probabilities are 35 percent lower among lapsers than non-lapsers.

Although the Hendel and Lizzeri (2003) model assumes symmetric information and therefore precludes moral hazard, if we relax this assumption, an obvious explanation for the negative relationship between lapsing and service use is the presence of moral hazard. Individuals with long-term care coverage face relatively low costs for nursing home stays while for those who drop coverage completely (and whose policies lacked forfeiture provisions) face substantially higher costs. In this case even if there is no ex-ante difference in the risk faced by the two groups prior to the lapse, and the dropped policy does not indicate the arrival of new information about risk, those who let a policy lapse will be less likely to use long-term care simply because they face a higher price for such care

To test this possibility, we compare nursing home use among lapsers who lapse to no insurance with that of those who lapse to another insurance product. ${ }^{10}$ Specifically, we limit the sample to just the subset of individuals who in 1996 or 1998 report ever having let a policy lapse and estimate:

$$
\mathrm{NH} \_ \text {USE }=\mathrm{X} \beta_{1}+\beta_{2} \text { LAPSEINS }+\varepsilon
$$

LAPSEINS is an indicator variable for whether the individual who reports ever having lapsed also reports having insurance either in the interview in which they report ever having lapsed or in

\footnotetext{
${ }^{10}$ Some of those who lapse to another policy will have lapsed to less generous coverage and some to more generous policies. In either case the coverage provided will be greater than that available to those without insurance.
} 
a subsequent interview through 2000. All other variables are defined as before. For the sample of lapsers, the mean of NH_USE is 0.036

The results from OLS estimation of equation (2) are shown in Table 3; probit estimation produces similar results (not shown). We find no statistically or substantively significant difference in nursing home use between these two groups of lapsers. Indeed, those who lapse to another insurance policy (and who potentially are affected by moral hazard) are somewhat less likely to use a nursing home than those who lapse to nothing, although the difference is not significantly different from zero and is substantively small. We conclude that those who lapse are leaving the risk pool at least in part because they are of lower risk than initially believed.

\section{Conclusion.}

Efficient provision of insurance requires insurance against reclassification risk as well as against the risk of the event itself. The difficulty with providing insurance against reclassification risk is that while ex-ante it is valued by individuals, ex-post, individuals who learn that they are lower than anticipated risk have an incentive to drop out of the insurance market. Absent a mechanism that forces individuals to retain policies (e.g. up-front payment of all premiums) these newly lower risk individuals will let their policies lapse. Consistent with this type of market failure, we compare nursing home admission rates for those who let their long-term care insurance policies lapse with those who maintain coverage and find that those who let their policies lapse are approximately one-third less likely to enter a nursing home than those who do not. These results do not appear to be explained by ex-post moral hazard effects of maintaining insurance coverage.

It is worth noting that although the evidence on lapsation is consistent with a dynamic reclassification risk story, we do not believe that the arrival of new information about risk can fully explain the observed lapsation behavior. There are likely a large set of individual circumstances that also affect lapsation behavior. One possibility is that people make mistakes, either ex-ante in purchasing the policy or ex-post in letting it lapse when this is not optimal. The 
high initial lapsation rate immediately following purchase (Figure 1) is consistent with some amount of ex-ante mistakes. It seems unlikely that new information could arrive sufficiently soon after the initial purchase to make it optimal to drop coverage immediately for such a large fraction of policy holders. Another possibility is that uninsured negative wealth or income shocks may create difficulties in one's ability to pay premiums or qualify one for Medicaid coverage. Such explanations would suggest that market failures in other insurance markets - such as the market for income insurance - contribute to market failures in long-term care insurance. Exploring the empirical relevance of these other factors behind lapsation behavior is an interesting and important avenue for future work. 


\section{Data Appendix}

In this appendix we describe in detail our measure of lapsation, the exact variables and years used to construct our "at risk" population and our measure of long-term care use.

\section{$\underline{\text { Defining lapsation }}$}

Our choice of the long-term care insurance market is driven in part by the importance of long term care insurance and the surprisingly limited nature of the market. However, it is also motivated by a question in the Health and Retirement Study that specifically asks about lapsed long-term care policies. As we noted the text, the specific question is:

"Have you ever been covered by any long-term care insurance that you cancelled or let lapse."

Although the HRS asks a similar question about lapses of life insurance policies, we believe that the long-term care insurance context provides us with a more accurate measure of genuine lapses. Long-term care policies are written to be of indefinite term; they remain in force with a given set of benefits for as long as the policy holder pays the specified premium. In contrast to this practice, it is common in the life insurance market to write long-term contracts that provide coverage for a finite span of time, such as 20 years. There is thus the very real possibility that an individual whose policy ended because it reached the end of the term would report the end as a lapse. In using these reports of lapses of life insurance policies we would be introducing substantial measurement error.

An alternative way to measure lapsation might be to examine reported changes in long-term care insurance coverage between interviews. However, such an approach we will only pick up people who lapse to no insurance, and miss people who lapse to other contracts. Moreover, it is likely that a measure based on changes in reported values will imply excessive switching of categories (McGarry, 1995) resulting in an error ridden classification. If we calculate a lapse rate based on changes reported long-term care insurance coverage between the 1998 and 2000 waves 
of the survey, we find lapsation rates approaching 50\%, an implausibly high rate relative to industry estimates (SOA, 2002). By contrast, the lapse rate calculated based on responses to the direct question discussed above, produce lapsation rates that are quite close to industry estimates. ${ }^{11}$

There is, however, one important limitation to the reported lapsation variable. At each interview, the question about the lapsing of a long-term care policy (perhaps surprisingly) asks the respondent whether they have ever lapsed on their policy. Once an individual gives an affirmative response, he should continue to reply in the affirmative in all subsequent interviews. The data reveal that this is unlikely to be the case. For example, of the 275 people who report in 1996 having ever lapsed on a long-term care policy and who answer this question again in 1998, only 20 percent once again report ever having had a lapsed policy. We suspect that this is because they are confused about the window of time to which the question refers. Many questions in the HRS ask about changes since the previous interview and respondents may thus be condition to respond as if this were the appropriate time frame. Indeed the nearly identical question about the lapsing of life insurance policies does ask only about those lapses occurring since the previous interview.

\section{Sample selection}

The HRS survey began in 1992 with a sample of individuals born in the interval 1931 to 1941 . A companion survey (initially referred to as the Asset and Health Dynamics of the Oldest Old-AHEAD) was fielded in 1993 for a sample of respondents born in 1923 or earlier. The initial

\footnotetext{
${ }^{11}$ Insurance companies estimate that each year approximately 7 percent of those with coverage let their coverage lapse. If we apply this 7 percent annual probability of lapsing to the 10 percent of the HRS sample with long term care insurance in 1998, we would predict that in a two year time period 1.4 percent of respondents would have a policy that lapsed. This figures is surprisingly close to the 1.9 percent of respondents who in 1998 report having "ever" lapsed on a long-term care insurance policy Thus, we believe that the data on reported lapses are accurate insofar as they represent true lapses of coverage, but are not accurate with respect to the timing of the lapse.
} 
HRS cohort was interviewed in 1992, 1994, 1996, 1998 and 2000. ${ }^{12}$ The older AHEAD cohort was in 1993, 1995, 1998 and 2000. In 1998 two new cohorts were added to the HRS; one comprised of those born between the years 1924 and 1930 and one of those born between 1942 and 1947. These respondents were interviewed in 1998 and 2000. All cohorts will continue to be interviewed biennially.

Although the HRS provides the best available data on long-term care insurance for a population representative sample, reliable questions about coverage were not available in the 1992, 1993 or 1994 interviews and information about the lapsing of past policies was not recorded in 1992, 1993, 1994 or 1995. Because we define our population at risk to consist of those who either report that they have a long-term care policy or who report that they had a policy that they let lapse, these data are crucial. We are therefore limited in the number of years of data on which we can draw.

Specifically, for the HRS cohort we cannot use the 1992 and 1994 interviews and thus comprise our sample of those who report a lapsed policy in the 1996, 1998 or 2000 interview, or who report having long-term care insurance in 1996 or 1998. We do not include people who only report insurance in 2000 (without ever having reported a lapse) because such people are not "at risk" of lapsing during the period of time over which we observe them. Subsequent nursing home stays for those in our sample could be reported in either the 1996, 1998 or 2000 interviews.

For the AHEAD cohort individuals are included in our sample if they report a lapsed policy in 1998 or 2000, or if they report having insurance in 1995 or 1998. In this case nursing home stays include those recorded in the 1998 or 2000 interviews. For the two newest cohorts we include in the sample individuals who report lapsing in 1998 or 2000 or report having insurance

\footnotetext{
${ }^{12}$ Preliminary data are available for 2002 but we do not employ these here because of difficulties with the "exit interviews."
} 
in 1998, and use reports of nursing home stays from the 1998 or 2000 interviews. ${ }^{13}$ Our final sample consists of 3,649 indivdiuals who were at risk at some point during the observation window; of these, 291 individuals report a lapse in 1996, 451 in 1998 and 331 in 2000.

A potential limitation to this approach is that it is possible that nursing home use occurred prior to the lapsation (e.g.. someone who let a policy lapse in 1999 but had a nursing home stay in 1998). To test the importance of this issue we restricted our definition to nursing home use to stays that we can identify as occurring strictly after a reported lapse. This decreases sample size substantially because we cannot use data on lapses in 2000 . However, despite the smaller sample, our results echo those for the larger sample and if anything offer even stronger support for our conclusions that those who let policies lapse are less likely to enter a nursing home than those who do not.

We also verified that our central finding is robust to two alternative methods of defining the sample of at risk individuals. We experimented with both a more inclusive sample definition which includes all individuals in the survey in the at risk population even if they never have reported having insurance - and a more restriction sample definition which only includes individuals for whom we have observed insurance coverage and only counts them as lapsing if we observe a reported lapse in an interview subsequent to the one in which they have reported having insurance. In both cases, our finding that individuals who let a policy lapse are less likely to subsequently enter a nursing home than individuals who do not let their policy lapse was robust both substantively and statistically.

\footnotetext{
${ }^{13}$ Although the survey follows respondents of all cohorts into nursing homes, the first interviews are of the non-institutional population only. Those first interviewed in 1998 could not therefore be in a nursing home at the 1998 interview, although they could have had prior admissions.
} 


\section{References}

Brown, Jeffrey and Amy Finkelstein. 2004. "Supply or Demand: Why is the Market for LongTerm Care Insurance So Small?” NBER Working Paper 10782

Cochrane, John. 1995. "Time Consistent Health Insurance.” Journal of Political Economy 103 (3): 445-473.

Congressional Budget Office. 2004. "Financing Long-Term Care for the Elderly." Government Printing Office: Washington, DC. April.

Finkelstein, Amy and Kathleen McGarry. 2003. "Private Information and Its Effect on Market Equilibrium: New Evidence from Long-Term Care Insurance.” NBER Working Paper \#9957.

Health Insurance Association of America (HIAA) 1993. "Survey Results: Why Do Poliycholders Terminate Their Long-Term Care Insurance Policies?” Washington DC.

Health Insurance Association of America (HIAA) 2000. "Who Buys LTC Insurance in 2000?" Washington DC.

Hendel Igal and Allessandro Lizzeri. 2003. "The role of commitment in dynamic contracts: evidence from life insurance.” Quarterly Journal of Economics. February: 299-327.

Hirshleifer, Jack (1971). "The Private and Social Value of Information and the Reward to Inventive Activity," American Economic Review 61, 561-574.,

Kaiser Family Foundation (2003). "Regulation of Private Long-Term Care Insurance: Implementation Experience and Key Issues.” The Henry J. Kaiser Family Foundation, Washington DC.

Murtaugh, Christopher, Peter Kemper and Brenda Spillman. 1995. "Risky Business: Long-Term Care Insurance Underwriting." Inquiry 32 pp. 371-384.

Norton, Edward. 2000. "Long-term Care." In AJ Culyer and JP Newhouse (eds) Handbook of Health Economics vol 1, chapter 17. Elsevier Science.

Pauly, Mark, Howard Kunreuther and Richard Hirth. 1995. "Guaranteed renewability in insurance." Journal of Risk and Uncertainty 10, 143-156.

Society of Actuaries. 2002. "Long-Term Care Experience Committee InterCompany Study 1984 - 1999.” http://www.soa.org/sections/intercompany_study.pdf

Weiss Rating Inc. 2002. “Weiss Ratings' Consumer Guide to Long-Term Care Insurance.” Palm Beach Gardens, Fl. 


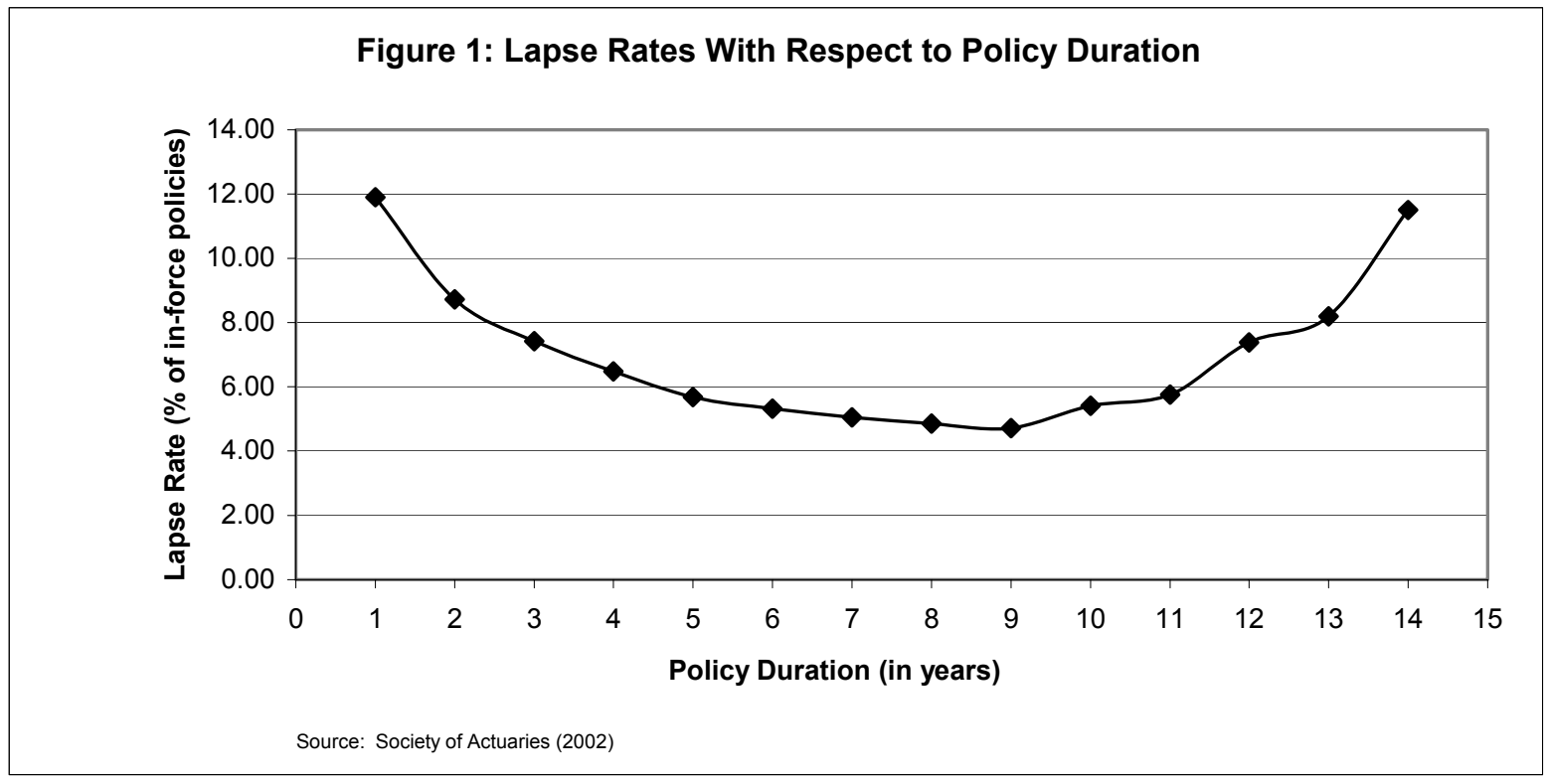

Figure 2: Lapse Rates By Amount of Front-Loading

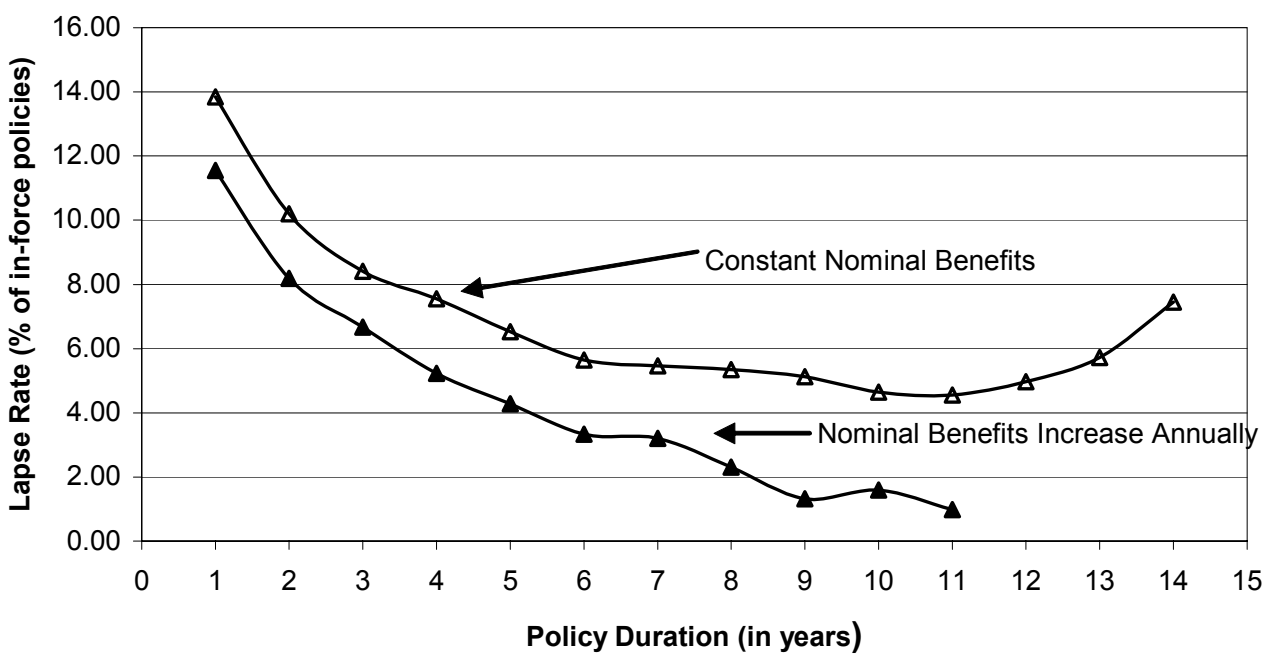

Source: Society of Actuaries (2002) 
Table 1: Descriptive statistics on sample

\begin{tabular}{lll}
\hline \hline & Individuals who lapse & $\begin{array}{l}\text { Individuals "at risk" who do } \\
\text { not lapse }\end{array}$ \\
\hline Average Age & 66.1 & 67.2 \\
Percent Male & 43.5 & 44.5 \\
Percent Married & 63 & 72.1 \\
Median Income & 28,150 & 39,000 \\
Median Net Worth & 126,000 & 218,000 \\
Less Than High School & 27.8 & 16.5 \\
High School & 30.2 & 34 \\
Some College & 22.5 & 22 \\
College or More & 19.5 & 28 \\
$\mathrm{~N}$ & 987 & 2662 \\
\hline \hline
\end{tabular}

Notes:

Sample definition: Individuals who lapse are those who report lapsing in 1996, 1998 or 2000. Individuals "at risk" for lapsing but who do not lapse are those who have insurance in 1995, 1996, or 1998 (we do not include 2000 because such individuals are not at risk for us observing them lapse) and do not ever report lapsing (in 1996, 1998, or 2000). Note that reported lapsation is not available in 1995. See Appendix for more details.

Variable definitions: All means are weighted. All variables that are time varying are defined based on the first time the individual was interviewed in the sample that we are using (i.e. 1995 for AHEAD, 1996 for HRS, 1998 for CODA or for War Baby). 
Table 2: The relationship between lapsation and subsequent nursing home use

\begin{tabular}{lll}
\hline \hline & No controls & Controls for Insurance \\
& & Company Risk Classification \\
& $(1)$ & $(2)$ \\
\hline Coefficient on LAPSE & $-0.024^{* *}$ & $-0.025^{* * *}$ \\
$\mathrm{~N}$ & $(0.010)$ & $(0.009)$ \\
\hline \hline
\end{tabular}

Note: Table reports results from linear probability estimation of equation (1). Robust standard errors are in parentheses. ${ }^{* * *}, * *$ indicates statistical significance at the 1 percent and 5 percent level respectively.

Dependent variable is whether individual subsequently goes into a nursing home (mean is 0.07). LAPSE is an indicator variable for whether individual let their insurance policy lapse. Column headings define the other covariates in the regression. See text for further details. Results from probit estimation are similar (not shown).

Table 3: Subsequent nursing home use of those who lapse to new insurance contract compared to those who lapse out of the market completely

Coefficient on LAPSEINS

Coefficient on LAPSEINS

$\mathrm{N}$

Note: Table reports results from linear probability estimation of equation (2). Robust standard errors are in parentheses. Dependent variable is whether individual subsequently goes into a nursing home (mean is 0.035). LAPSEINS is an indicator variable for whether individual bought new insurance policy after letting their policy lapse. Column headings define the other covariates in the regression. See text for further details. Results from probit estimation are similar (not shown).
No controls

(1)

Controls for Insurance

Company Risk Classification

(2)

$-0.002$

$(0.017)$

(0.016)

668
- from probit estimation are similar (not shown). 